\title{
Sistemas deliberativos em perspectiva meso: a abordagem dos subsistemas aplicada aos conselhos de políticas públicas em Belo Horizonte ${ }^{1}$
}

\author{
Eduardo Moreira da Silva \\ Antonio Carlos Andrade Ribeiro
}

\section{Introdução}

O estudo da democracia deliberativa evoluiu muito nos últimos anos. Desde seu surgimento, quando foram formulados os primeiros modelos teóricos (Habermas, 1995, 2003; Bohman, 1996), passando pela discussão procedimental em torno de quais arranjos institucionais poderiam melhor promover processos deliberativos inclusivos e capazes de aumentar a intensidade da democracia (Avritzer, 2009; Fung, 2004), até chegar à vasta literatura construída a partir de inúmeros estudos de casos focados no perfil dos participantes, na estrutura organizacional, nos seus efeitos sobre a distribuição do poder e na efetividade das instituições participativas (Avritzer, 2010; Pires, 2011).

Recentemente, a literatura sobre o tema deu mais um passo em direção à construção de uma teoria deliberativa mais robusta. Embora as formulações teóricas tenham retornado a um patamar de abstração menos elevado, ainda existe um fosso entre a dimensão teórica e o trabalho empírico realizado para testar as teorias. Nesse sentido, a formulação de uma teoria deliberativa elaborada de um ponto de vista sistêmico pode contribuir significativamente para a compreensão das democracias contemporâneas.

A perspectiva dos sistemas deliberativos (SD), como vem sendo chamada, concebe os resultados dos processos democráticos como produtos de um sistema de instituições políticas integradas por diversos mecanismos. Assim, o processo democrático é visto como um "liga e desliga" dos múltiplos componentes desse sistema por onde circulam ideias, propostas, interesses e outros elementos que estão envolvidos no processo de construção de decisões políticas. Esse modelo sustenta que só podemos ter uma compreensão adequada das democracias contemporâneas se apreendermos os

\footnotetext{
1 Versão anterior do presente texto foi apresentada no II Encontro Internacional Participação, Democracia e Políticas Públicas, realizado em Campinas, nos dias 27 a 30 de abril de 2014. Agradecemos a todos os comentários e críticas recebidos, em especial, a Roberto Pires (Ipea) pela leitura atenta do trabalho. Nossos agradecimentos também aos comentários e sugestões dos professores Leonardo Avritzer, Claudia Faria, Débora Rezende e Ricardo Fabrino, antes da submissão do artigo, e aos dois pareceristas da revista pelas valiosas contribuições.
} 
mecanismos que sustentam esse sistema. O processo deliberativo não pode ser compreendido se abordado apenas no nível micro. É preciso entender como as diversas instituições políticas influenciam umas às outras.

Neste artigo, buscamos oferecer uma contribuição a esse debate a partir de um estudo empírico. Consequentemente, propomos abordar o estudo dos sistemas deliberativos de uma perspectiva de nível meso, nomeada aqui de subsistemas deliberativos. Estes correspondem aos subconjuntos dentro dos sistemas deliberativos (nível macro) formados pelas arenas que os compõem (nível micro). Subsistemas podem ser delimitados por determinados critérios que apresentamos na segunda seção deste artigo, "A teoria deliberativa e a visão sistêmica na produção de políticas públicas".

O objeto do estudo analisado aqui é o subsistema dos conselhos de política da cidade de Belo Horizonte, capital do estado de Minas Gerais - Brasil. Este é formado por 22 conselhos, para os quais conseguimos levantar informações. Nós abordamos esse subsistema a partir de um único mecanismo de integração, qual seja, a coafiliação dos conselheiros em mais de um conselho, doravante conectores. A literatura sobre o tema tem destacado esses mecanismos considerando o papel dos representantes do poder público nos conselhos, entretanto, deixando escapar a dimensão da participação dos atores da sociedade civil.

Para realizar o estudo, aplicamos a metodologia de análise de redes sociais, especificamente técnicas de análise de redes de afiliação (ou análise de redes de dois modos). Nós acreditamos que essa metodologia é a mais apropriada para testar o modelo dos sistemas deliberativos, cujos elementos fundamentais são os mecanismos que conectam o sistema. Sem esses mecanismos seria impossível produzir resultados, por isso nosso argumento destaca a necessidade de entender os mecanismos de interação dos sistemas deliberativos para explicar seus resultados (como e por que foram produzidos).

Os resultados mostram que o subsistema dos conselhos de políticas de Belo Horizonte, em outubro de 2014, encontrava-se totalmente integrado por meio da coafiliação dos conselheiros. Identificamos papéis diferentes desempenhados pelos conselheiros representantes do poder público e os da sociedade civil. No primeiro caso, os dados apontam para uma especialização, já identificada pela literatura, dos conselheiros do poder público. Estes têm a função de realizar a integração interna desse subsistema. No segundo caso, embora tenham menor importância como conectores internos do subsistema analisado, nossa análise sugere que os representantes da sociedade civil são, em hipótese, os conectores externos do subsistema dos conselhos de política. Isto é, eles representam um dos mecanismos que conectam o subsistema analisado aos outros subsistemas do sistema deliberativo. Além disso, esses atores cumprem a função de criar laços diretos entre alguns conselhos.

A primeira seção deste artigo apresenta a teoria dos sistemas deliberativos. Destacamos os principais aspectos desse quadro analítico. Na segunda seção, oferecemos 
SISTEMAS DELIBERATIVOS EM PERSPECTIVA MESO

nossa contribuição ao propor a abordagem dos subsistemas deliberativos. Nós defendemos que essa abordagem é essencial para o desenvolvimento das pesquisas empíricas nesse campo. Na seção seguinte, apresentamos as hipóteses elaboradas com base na literatura abordada. Na quarta seção, explicitamos aspectos da metodologia aplicada: notas sobre a análise de redes sociais (ARS) e a descrição do dado analisado. $\mathrm{Na}$ quinta seção, descrevemos as características do subsistema considerando a integração via coparticipação dos atores nele imersos. Por fim, nas considerações finais, apontamos caminhos para que o trabalho realizado aqui seja levado adiante. Sob esse aspecto, destacamos a importância de produzir dados tendo em vista os demais mecanismos que podem contribuir para a integração do subsistema de conselhos, a identificação e a análise de outros subsistemas, segundo os critérios que destacaremos, e a construção de dados que permitam entender melhor a função dos atores da sociedade civil como conectores de subsistemas.

\section{A teoria deliberativa e a visão sistêmica na produção de políticas públicas ${ }^{2}$}

O tema da legitimidade das decisões produzidas em regimes democráticos foi alçado ao centro principal das atenções de um significativo conjunto de autores, desde o início dos anos 1990, com emergência de uma ampla produção teórica nomeada por Dryzek (2010) como deliberative turn. Os propositores do modelo deliberativo partilham o entendimento de que a legitimidade da democracia depende, em parte, da qualidade da deliberação realizada pelos cidadãos e seus representantes (Mansbridge et al., 2012).

No âmbito internacional, a análise dos diferentes fóruns deliberativos e de suas relações com o sistema político tem ganhado a atenção recente de autores que se dedicam ao estudo da teoria deliberativa, reunidos em torno da discussão sobre o que denominaram de um modelo sistêmico de democracia deliberativa. Embora a abordagem sistêmica não seja inteiramente nova, inclusive no âmbito da teoria deliberativa, na qual já tinha sido objeto da atenção de Habermas (2003), o enfoque dado à questão pode ser considerado promissor, na medida em que busca propor uma análise das diversas instâncias deliberativas do sistema político e suas formas de interação mútua. Assim, busca-se observar a deliberação no âmbito tanto dos corpos legislativos quanto das "pequenas iniciativas deliberativas" (Mansbridge et al., 2012, p. 1).

A origem da discussão sobre um sistema deliberativo está em um artigo publicado por Mansbridge (2009, p. 207), no qual a autora sugere a influência da "conversação cotidiana" no "amplo sistema deliberativo das democracias", isto é, a conversação entre representantes formais e informais em fóruns públicos, na mídia, entre ativistas políticos em espaços privados sobre assuntos que o público deveria discutir. Em outros termos, esteve em relevo, nesse primeiro momento, a proposição da existência de um amplo

\footnotetext{
${ }^{2}$ Esse tópico é uma versão reformulada de parte de um texto anteriormente apresentado no IX Encontro Anual da Associação Brasileira de Ciência Política. Agradecemos aos comentários preciosos de Adrian Lavalle recebidos naquela ocasião, a partir dos quais o presente artigo foi elaborado.
} 
sistema deliberativo, que seria influenciado pelas discussões realizadas entre os cidadãos nos espaços formais e informais de discussão sobre as questões e os assuntos relacionados à política. Ela faz questão de afastar a visão mecanicista do termo, como se observa na passagem abaixo:

Usar a palavra "sistema" não implica que as partes do todo tenham uma
relação mecânica ou perfeitamente previsível uma com a outra, embora
estes atributos sejam conotações das palavras "sistema" e "sistemático" no
discurso comum. Em vez disso eu quero sugerir uma inter-relação entre as
partes, de modo que uma mudança em uma delas tende a afetar a outra
(Mansbridge apud Mendonça, 2013, p. 2, tradução livre).

Trata-se de uma abordagem diferente daquela utilizada na teoria sociológica, tal como concebido por Luhmann e Parsons. Eles estão tratando do que Habermas (2003) nomeou abordagens empiristas do poder, que "não ignoram a impregnação normativa do poder político estruturado conforme o direito, apenas o reduzem ao poder social" (Habermas, 2003, p. 11).

A abordagem é estrutural e denota um processo de especialização das esferas da vida social, decorrente do processo de modernização, que culmina em esferas relativamente autônomas, tais como a economia, a política, a cultura e a social. Haveria lógicas próprias a cada uma delas, o que fica claro em Habermas e sua concepção tripartite da sociedade moderna (Estado, mercado e mundo da vida). Duas esferas operam pela lógica sistêmica (mercado e Estado), regidos pelo dinheiro e pelo poder, respectivamente. No mundo da vida a lógica seria a solidariedade.

A relação entre agência e sistemas derivada daquela concepção da sociedade está condicionada pelos incentivos sistêmicos gerados por cada uma das esferas, que influenciaram o comportamento dos atores sociais. Isto é, na esfera do mercado, os atores se orientam para maximizar a possibilidade de obter lucro, pois é a lógica do dinheiro que orienta, prioritariamente, a ação dos atores. No Estado, cujo incentivo principal é a luta e a disputa pelo poder, os atores agirão estrategicamente para conquistar os recursos que potencializam a sua influência dentre os demais atores. Por fim, no mundo da vida, a interação entre os atores é regida pelo princípio da solidariedade, termo utilizado por Habermas "como um conceito de uma teoria da sociedade, não como um conceito pura e simplesmente normativo" (Habermas, 2003, p. 22, nota 11).

É importante destacar, ainda, que a própria utilização que o autor faz da teoria dos sistemas recebe adaptações na sua teoria do discurso. Vejamos: "a teoria do discurso considera o sistema político como um sistema de ação ao lado de outros, não o centro, nem o ápice, muito menos o modelo estrutural da sociedade" (Habermas, 2003, p. 25).

Mais recentemente, Mansbridge et al. (2012) definiram um sistema como 
um conjunto de partes diferenciadas, mas interdependentes, com funções distribuídas e conectadas de forma a construir um todo complexo. Ele requer diferenciação e integração entre as partes, alguma divisão funcional de trabalho, bem como alguma interdependência funcional de forma que a mudança em um componente redundará em mudanças em outros. Ele envolve conflito e solução de problemas políticos baseados na fala. Por que a fala? Por ser uma forma de comunicação menos exigente que pode envolver desde a demonstração, a expressão e a persuasão até o próprio debate (Mansbridge et al., 2012, p. 4, tradução livre).

O modelo sistêmico seria, então, um instrumental analítico importante para refletir sobre a influência de cada uma das partes sobre o todo e vice-versa. Antes de passarmos à descrição e à análise crítica do modelo, no entanto, faz-se necessário apresentar suas características principais, suas origens históricas e as categorias analíticas propostas pelos autores que têm se dedicado à proposição do modelo.

$\mathrm{Na}$ introdução do livro Deliberative systems (Parkinson e Mansbridge, 2012), J. Mansbridge, J. Bohman, S. Chambers, T. Christiano, A. Fung, J. Parkinson, D. F. Thompson e M. E. Warren buscam uma resposta analítica vigorosa à difícil tarefa de repensar as relações e as dinâmicas estabelecidas entre os diversos fóruns deliberativos. Presentes em vários regimes democráticos, estes funcionam em contextos de larga escala. Em outros termos, o principal objetivo do livro é oferecer um modelo para repensar a relação entre deliberação e democracia em contextos caracterizados pela vasta extensão territorial, pela pluralidade de atores e pela multiplicidade de arenas deliberativas.

Percebe-se, portanto, no objetivo do livro uma proposta de ajuste no foco central do modo como as arenas deliberativas vinham sendo estudadas, isto é, avaliavam-se individualmente as arenas e fóruns deliberativos, a partir da sua capacidade de incrementar a legitimidade das decisões políticas ali produzidas. Os autores se referem aos estudos sobre a qualidade da deliberação tanto nos corpos legislativos quanto nas pequenas iniciativas deliberativas. Constatam, no entanto, a necessidade do desenvolvimento de pesquisas com foco em um amplo sistema interdependente, dado que nenhuma arena deliberativa, isoladamente, teria a capacidade de incrementar a legitimidade da maior parte das decisões e das políticas produzidas pelos regimes democráticos (Mansbridge et al., 2012, p. 1-2, tradução livre). Tem-se, assim, a passagem de um nível micro de análise ao nível macro.

A abordagem sistêmica traria três importantes contribuições. Em primeiro lugar, permite pensar sobre a democracia deliberativa em contextos societais de larga escala. Com isso, busca-se oferecer uma nova solução a um desafio antigo da teoria democrática deliberativa, qual seja: o problema da escala. Isso porque a deliberação face a face só é viável em pequenos grupos, pois a ampliação dos atores afeta e pode até inviabilizar a qualidade dos processos de discussão e deliberação (Parkinson, 2006). Isto é, a literatura acerca da participação política destaca como variável relevante para seu estudo a 
questão da extensão territorial (escala) dos locais nos quais ela se desenvolve. Essa discussão está presente em autores "precursores" do modelo da democracia participativa, tal como Macpherson (1978) e Pateman (1992), que já apontavam como possíveis limites aos arranjos institucionais inseridos no modelo a ampliação do número de participantes e dos horizontes nos quais ela se desenvolve.

Os diversos modelos de análise da democracia, tanto na corrente deliberativa quanto na representativa, reconhecem que as deliberações realizadas nas diferentes arenas são organizadas pelos estados ou unidades subnacionais e estão confinadas a essa esfera. Nesse sentido, questionam Mansbridge et al. (2012), como se poderia afirmar que a sociedade como um todo, o demos, as pessoas que a compõem deliberam em conjunto? A resposta dos autores caminha no sentido de afirmar as potencialidades de pensar em termos de um modelo sistêmico, uma vez que ele "expande a escala da análise para além da consideração dos espaços isoladamente e nos permite pensar acerca das deliberações e interações desenvolvidas entre os espaços ao longo do tempo" (Mansbridge et al., 2012, p. 2, tradução livre).

A segunda contribuição do modelo sistêmico advém da proposição de analisar a divisão de trabalho entre as partes do sistema, mas sem a exigência de que cada uma delas seja caracterizada por todas as virtudes da boa deliberação. Soma-se a essa consideração o fato de que o relacionamento entre as partes nem sempre é marcado pela relação de complementaridade. Os autores mencionam a existência, também, de alguns momentos de deslocamentos (displacement) no sistema. Nessa circunstância, mesmo quando a deliberação de uma única parte pode ser avaliada como problemática, isso não necessariamente produzirá um impacto negativo sobre o todo, pois as outras partes podem compensar essa deficiência. Inversamente, uma arena institucional que pareça exemplar do ponto de vista da deliberação ali produzida pode parecer menos benéfica sob a perspectiva do sistema. Em outros termos, a existência de deslocamentos pode não ser totalmente prejudicial ao sistema deliberativo, na medida em que não se considera que cada parte tenha necessariamente uma única função. Além do mais, como algumas partes podem compensar a deficiência de outras, mesmo com a presença de deslocamentos é possível chegar à deliberação democrática (Mansbridge et al., 2012, p. 2, tradução livre).

A terceira contribuição da abordagem sistêmica relaciona-se à introdução de grandes questões contextuais que impactam os espaços individuais e conformam as possibilidades de deliberações efetivas (Mansbridge et al., 2012, p. 2, tradução livre). Logo, uma abordagem sistêmica nos permite observar mais claramente onde o sistema pode ser aperfeiçoado e, assim, recomendar instituições ou outras inovações que possam suplementar o sistema em suas áreas de fraqueza (Mansbridge et al., 2012, p. 4, tradução livre).

A seguir, Mansbridge e demais autores se dedicam a analisar três elementos característicos dos sistemas políticos que, usualmente, não são considerados como parte 
do exercício da deliberação democrática. Para tanto, explora-se o papel desempenhado pelos experts, pelos protestos e formas de pressão da sociedade e, por fim, pela mídia partidária. A presença de experts em espaços e instituições tende a aumentar a qualidade da informação disponível para a deliberação mas, simultaneamente, desrespeita o saber popular e representa um problema relacionado à inclusão democrática de todos os cidadãos leigos naquele assunto. Isto é, são excluídos do processo decisório os cidadãos não especialistas.

No que se refere aos protestos e formas de pressão da sociedade, a distinção analítica importante refere-se à consideração de que esses elementos podem violar a condição ideal de deliberação, na acepção habermasiana, segundo a qual deve prevalecer a força do melhor argumento. Mansbridge et al. (2012) sugerem que uma teoria sistêmica consistente requer a elaboração de uma interpretação capaz de estabelecer uma linha divisória entre a pressão e a persuasão, em condições nas quais se espera a prevalência do melhor argumento. A influência não deliberativa pode advir de várias formas e as duas mais difíceis de ser enfrentadas pela teoria deliberativa relacionam-se ao dinheiro e à pressão. Esses dois elementos podem funcionar como mecanismos de distinção entre os participantes de uma arena deliberativa, isto é, a presença desses elementos em arenas deliberativas pode romper com os pressupostos da igualdade, do respeito mútuo e da não coerção entre os participantes. Por outro lado, os protestos e as formas de pressão da sociedade podem cumprir um importante papel, no contexto das arenas deliberativas, relacionado ao fato de conseguirem inserir, na agenda dessas instituições, as demandas e temáticas vocalizadas por aqueles atores que estão, geralmente, excluídos desses espaços (Young, 2000).

Por fim, no que se refere à atuação da mídia partidária, embora seja "parte crucial do sistema deliberativo em qualquer democracia moderna, ela não tem desempenhado um papel substantivo na teoria deliberativa recente" (Mansbridge et al., 2012, p. 19, tradução livre). A análise sistêmica da mídia desenvolvida pelos autores coloca em foco três critérios: o epistêmico, o ético e o das funções democráticas desempenhadas por ela nos sistemas deliberativos. No que se refere ao primeiro critério, a "mídia partidária" pode incrementar a transmissão de informações confiáveis e úteis, que ajudam os cidadãos a interpretar os fatos e produzir conexões entre estes e as políticas públicas, tornando-se cidadãos críticos e vigilantes. Por outro lado, também têm crescido as reportagens partidárias nos EUA que provocam a falsificação dos fatos e a disseminação de informações falsas. Em relação ao critério ético, as notícias e os outros meios de comunicação podem afetar o grau de civilidade e de respeito entre os cidadãos. Certos tipos de notícias partidárias podem incrementar o grau de incivilidade entre os cidadãos, mas não está claro se "partidarismo" (partisanship) é, em si mesmo, incivil ou envolve a falta de respeito entre os cidadãos. Finalmente, a mídia pode desempenhar um importante papel de inclusão política democrática. Embora a internet seja uma fonte que propicia o aumento da informação acerca da política obtida pelos cidadãos, ela pode 
dividir os cidadãos e debilitar a função deliberativa da inclusão política (Mansbridge et al., 2012, p. 21).

Após a caracterização dos SD, os autores passam a descrever alguns problemas da abordagem sistêmica, por meio da apresentação de cinco patologias que a caracterizariam. A primeira delas foi denominada de tight-coupling e diz respeito às situações nas quais as partes do sistema estão fortemente acopladas umas às outras e, por isso, existe uma dificuldade para que os mecanismos de correção se façam presentes e atuantes. A segunda está relaciona a uma condição contrária à primeira, ou seja, uma situação denominada de decoupling, que se refere a um grau de dissociação tão alto entre as partes do sistema, que, mesmo quando se observa a existência de boas razões emergentes em uma das partes, esta não penetra as demais partes, tamanha é a separação entre elas. O terceiro problema é o da dominação institucional, isto é, aquela situação na qual uma das partes do sistema consegue exercer o domínio sobre todas as demais, tal como ocorre em sociedades autoritárias. A quarta patologia é a dominação social. Ela emerge quando um interesse social particular ou uma classe social específica influencia as demais partes do sistema deliberativo. Por fim, a quinta patologia ocorre quando os cidadãos, os legisladores e os gestores estão muito divididos em razão da forte adesão aos princípios ideológicos, às questões étnicas, à religião, ou outras clivagens capazes de acirrar a divisão entre as partes, de tal forma que não são consideradas como válidas as opiniões daqueles indivíduos pertencentes aos grupos diferentes dos seus.

Apesar de toda a consistência do modelo apresentado no livro e dos avanços descritos em cada um dos artigos, no sentido de caracterizar uma abordagem sistêmica da política deliberativa, alguns problemas permanecem em aberto. Em primeiro lugar, o caráter inédito e propositivo do modelo, no sentido de produzir interpretações capazes de descrever as contribuições oriundas das partes do sistema e seus possíveis impactos sobre o todo, ainda demanda avanços e aperfeiçoamentos. Não fica claro para o leitor como se dá a interação e a conexão entre as partes (Mendonça, 2013; Faria e Lins, 2013). Em segundo lugar, além do aperfeiçoamento do modelo teórico presente no primeiro ponto, permanece o desafio metodológico de construir técnicas de pesquisa capazes de captar a análise das partes em relação ao todo e vice-versa, ou seja, faz-se necessário o desenvolvimento de estratégias metodológicas capazes de indicar o modo como as partes se relacionam, a importância de cada uma das partes sobre o sistema e, também, os efeitos do sistema sobre as partes. Nesse sentido, um ponto de partida importante seria identificar os avanços acumulados no amplo conjunto de pesquisas realizadas sobre as iniciativas deliberativas desenvolvidas no âmbito microanalítico. Por outro lado, como mostramos adiante, as técnicas da análise de redes sociais oferecem as ferramentas analíticas que podem contribuir.

Mendonça (2013) identifica a ausência de conectores entre as diferentes partes do sistema. Nesse sentido, sugere aos democratas deliberativos prestar atenção nos 
SISTEMAS DELIBERATIVOS EM PERSPECTIVA MESO

seguintes elementos, que potencialmente poderiam induzir a conexão entre as partes: "1) a burocracia; 2) a mídia; 3) a circulação de participantes e seus representantes; 4) o desenho e as normas que constituem as instituições participativas" (Mendonça, 2013, p. 1). Percebe-se, a partir dos elementos sugeridos, um aperfeiçoamento do modelo e um avanço no sentido de pensar a realidade de outros países, para além da realidade anglosaxônica na qual se baseia a maior parte dos exemplos de sistemas mencionados por Mansbridge et al. (2012).

As pesquisas empíricas brasileiras desenvolvidas sob a perspectiva sistêmica tornam mais claras algumas limitações estruturais da teoria. Em primeiro lugar, Cunha e Almeida (2013), embora consigam mostrar e sustentar a presença de elementos sistêmicos nas normas que regem o funcionamento na área de assistência social, a pesquisa ainda é pensada de forma isolada em relação às demais áreas e arenas de políticas públicas, tal como os corpos legislativos, ou desacoplada das arenas de mesma natureza, mas de políticas temáticas diferentes. Faria, Silva e Lins (2012) apresentam um avanço ao pesquisar comparativamente duas áreas de políticas públicas (mulheres e assistência social), nos três níveis de governo. Consegue-se mostrar os fluxos e conexões estabelecidos entre os atores dos diferentes níveis. Ademais, mostram também o modo como os resultados do nível local podem se transferir aos demais (estadual e nacional) na realização das conferências de políticas públicas. No entanto, uma lacuna persistente refere-se à possível existência de conexões entre as instituições e os atores das duas áreas de política em questão e, também, destas com as demais.

\section{A abordagem dos subsistemas deliberativos}

O modelo teórico dos sistemas deliberativos disparou um adensamento da literatura sobre os processos da democracia deliberativa. Nesse contexto, nosso objetivo neste artigo é oferecer uma contribuição empírica que forneça elementos para o desenvolvimento desse modelo e, principalmente, contribua para diminuir o fosso entre a formulação teórica e as pesquisas empíricas. Nossa proposta consiste em introduzir na discussão uma abordagem em nível meso, o que facilita a investigação sobre os pressupostos teóricos elaborados na teoria dos sistemas deliberativos e possibilita o teste de algumas hipóteses formuladas a partir dela. Entre o micro (as arenas do sistema) e o macro (o conjunto de todas as arenas) que estruturam a teoria dos sistemas deliberativos, destacamos a existência de subgrupos de arenas deliberativas. Estes formam subsistemas que se permitem apreender mais facilmente. Conceitualmente, os subsistemas são subconjuntos de arenas dos sistemas deliberativos definidos por Mansbridge et al. (2012).

Subsistemas podem ser identificados por diferentes critérios. Inicialmente, sugerimos delimitá-los em função da natureza das arenas deliberativas, assim, podemos falar de subsistemas de fóruns participativos, tais como conselhos de política, audiências públicas, conferências etc.; ou falar de um subsistema de legislativos municipais ou 
estaduais. Um segundo critério para identificarmos subsistemas são as temáticas que orientam a ação política em torno da qual se organiza o processo deliberativo, assim, podemos falar em subsistemas da educação, da juventude, da assistência social, dos direitos da criança e do adolescente. Ainda, destacamos um terceiro critério para delimitação dos subsistemas deliberativos e que pode contribuir para a operacionalização empírica da teoria discutida aqui. Ele está relacionado à territorialidade, isto é, subsistemas podem ser definidos por sua vinculação a um espaço geográfico: uma cidade, uma região etc. Esses critérios não são excludentes e podem ser combinados para melhor delimitar um subsistema. Neste artigo, elegemos o primeiro critério (natureza das arenas deliberativas) como elemento principal na definição das arenas deliberativas do subsistema aqui analisado. Todavia, aplicamos também o terceiro critério para definir as fronteiras do subsistema.

A Figura 1 ilustra nosso argumento sobre os subsistemas. Nela podemos notar que os subsistemas se sobrepõem dentro do sistema deliberativo. Essa figura sugere dois tipos de elos de conexões nos sistemas deliberativos. O primeiro, formado por laços horizontais, liga as arenas deliberativas em subsistemas, o segundo é composto por laços verticais e conecta subsistemas diferentes a partir de suas arenas. Isso significa que alguns conectores atravessam subsistemas e atuam como pontes, que contribuem para a integração do sistema como um todo. A Figura 1 é uma representação de como se daria a conexão entre arenas dos subsistemas de conselhos de políticas, de conferências e de legislativos no nível municipal e a conexão entre esses subsistemas. A conexão entre os subsistemas se dá pela participação concomitante de membros das arenas $1,2,3,4$ e $5^{3}$.

\footnotetext{
3 Neste artigo, analisamos como atores políticos conectam as arenas dos subsistemas de conselhos. Observamos que esses mesmos conectores podem interligar subsistemas diferentes. Por exemplo, esse papel pode ser cumprido pelos vereadores, que, além de participar de vários conselhos, estão presentes em outras arenas como as câmaras municipais. A análise que apresentamos neste artigo sugere que os representantes da sociedade civil, nos conselhos de políticas públicas, podem ser os principais conectores entre esse subsistema e outros, por exemplo, o subsistema de conferências.
} 
Figura 1

Subsistemas deliberativos e seus elos de conexão

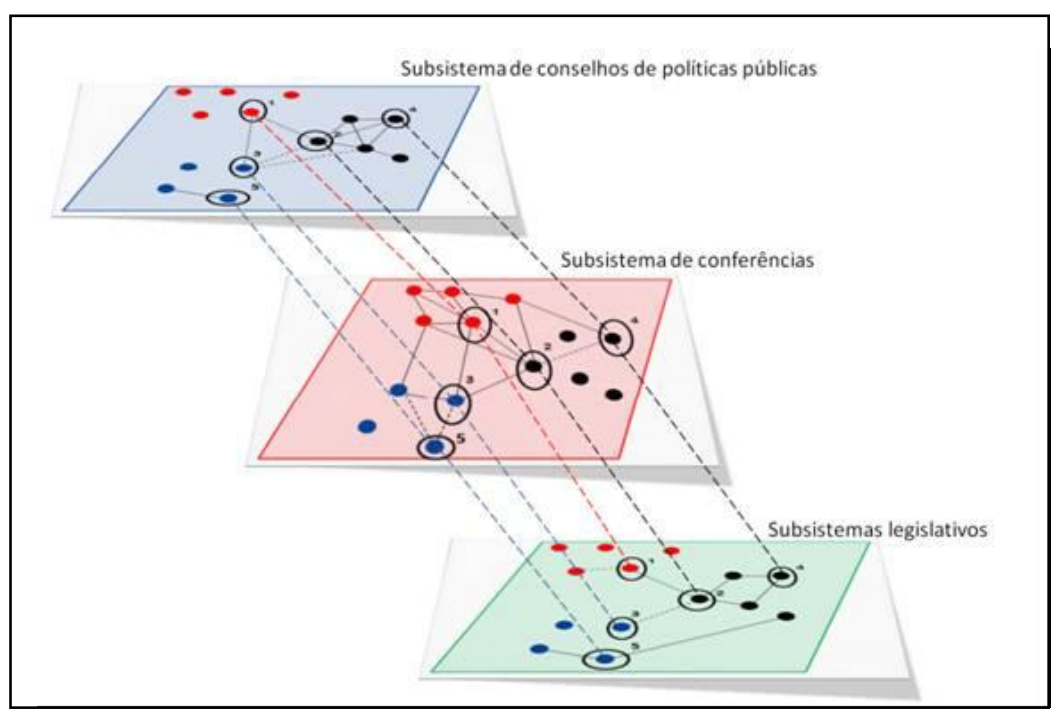

Fonte: Elaboração própria.

O objeto de análise neste artigo é composto pelos conselhos de políticas públicas da cidade de Belo Horizonte. Portanto, aplicamos a abordagem do subsistema apenas para estudar os laços horizontais de um sistema deliberativo. Outras combinações seriam possíveis, contudo o impacto direto da escolha feita recai sobre a construção do dado a ser levantado. Isto é, a definição dos critérios para identificar subsistemas afeta o levantamento dos dados que permitirão abordar empiricamente os sistemas deliberativos (ou subsistemas dentro destes).

Assumimos que, tal como formulada, a teoria dos sistemas deliberativos seria impossível de ser testada no momento. O que demanda criatividade dos pesquisadores interessados no tema. Por essa razão, a abordagem dos subsistemas se coloca como uma estratégia frutífera. Ela inova em relação às pesquisas empíricas a que nos referimos acima. Além disso, propõe um aporte à teoria que contribui para seu aperfeiçoamento. Particularmente, essa abordagem mantém em primeiro plano o que julgamos ser o elemento central da teoria dos sistemas deliberativos: a interação entre as arenas do sistema.

Além de delimitar os subsistemas, é necessário tornar claro quais são os mecanismos que conectam suas partes. Em nossa abordagem, estes podem ser formais ou informais, variando de regras claramente formuladas às relações de amizade. Para os subsistemas baseados na natureza das arenas deliberativas, sugerimos alguns elementos: a coafiliação dos atores que atuam no subsistema, as normas que regulam as relações entre as instituições, as relações de amizade entre os membros das instituições, a realização de reuniões entre os membros das arenas, e outras formas de colaboração, 
tais como promoção de eventos, emissão de pareceres, notas técnicas, posicionamentos conjuntos. Neste artigo foi possível abordar dois dos elementos conectores sugeridos: a integração do subsistema a partir da participação concomitante de conselheiros nos conselhos de políticas públicas analisados e, dentro das possibilidades oferecidas por nossos dados, o impacto das regras de constituição dos conselhos sobre a conectividade do subsistema de conselhos. Este é um artigo exploratório e visa apontar um caminho para operacionalizar a teoria dos sistemas deliberativos. Em trabalhos futuros, buscaremos investigar os efeitos de outros mecanismos sobre a integração do subsistema analisado.

Do ponto de vista metodológico, a abordagem dos subsistemas inova ao aplicar técnicas da análise de redes sociais para analisar os dados produzidos. Essa metodologia assume como pressuposto que as interações entre as partes devem ficar no primeiro plano da análise. Assim, destaca o impacto da estrutura que emerge de tais interações sobre os resultados alcançados pelas partes, tanto coletivamente quanto individualmente. Discorremos sobre a técnica empregada e a construção dos dados na seção de "Metodologia".

\section{Problemas e hipóteses}

A análise da literatura precedente sugere o desafio de realizar pesquisas empíricas capazes de explicitar a existência de um amplo sistema deliberativo nas democracias contemporâneas. Nesses termos, é possível sustentar a existência de um sistema participativo e deliberativo integrado no Brasil? Em caso afirmativo, quais seriam os componentes desses sistemas? As precondições normativas que induzem a formação de sistemas de gestão das políticas estão presentes apenas nas áreas da saúde (SUS) e assistência social (Suas) ou podem ser encontradas também em outras áreas? Quais seriam os principais conectores desses sistemas? Eles seriam formais ou informais? Embora não seja possível responder a todas essas questões no âmbito deste artigo, concentramos a atenção na última delas. Para tanto, buscamos testar a relevância de dois dentre os quatro conectores sugeridos por Mendonça (2013), quais sejam: 1) burocracia; 2) mídia; 3 ) relações entre os participantes e seus representantes; 4) normas e o desenho das instituições participativas. Concentramos a atenção no item $1^{4}$. A

\footnotetext{
${ }^{4}$ Um dos pareceristas deste artigo apontou a necessidade de analisar o impacto das regras de composição dos conselhos sobre a conectividade do subsistema analisado neste artigo. Sobre esse ponto, destacamos que os dados da pesquisa são limitados para aprofundar o tema, por isso decidimos informar nesta nota que encontramos alguns indícios relevantes que ajudam a melhorar o conhecimento acumulado sobre esse assunto. Essencialmente, notamos que as tais regras podem afetar a conectividade do subsistema quando há a reserva de assentos em um conselho para representação de outros conselhos. Em Belo Horizonte, no período analisado, esse foi o caso dos seguintes conselhos: (1) Conselho Municipal da Assistência Social, que tinha na sua composição representantes dos Conselhos Municipais do Idoso, dos Direitos da Criança e do Adolescente e dos Direitos das Pessoas com Deficiência Física; (2) Conselho Municipal de Educação, que tinha na sua composição representante do Conselho Municipal dos Direitos da Criança e do Adolescente; (3) Conselho Municipal de Saúde, que tinha na sua composição representantes dos Conselhos Municipais de
} 
hipótese central do artigo é de que os conectores mais expressivos são aqueles de natureza informal, baseados na dinâmica de funcionamento e interação entre as instituições e os atores, em especial aqueles oriundos da burocracia ${ }^{5}$.

\section{Metodologia}

A abordagem metodológica deste artigo é a análise de redes sociais (ARS). Com foco nas relações entre atores sociais (pessoas ou organizações), a metodologia leva o pesquisador a centrar-se nos mecanismos que integram partes isoladas. Nesse sentido, ela permite uma abordagem especial que inclui, ao mesmo tempo, o nível micro, meso e macro de análise. Assim, é possível entender tanto a importância dos atores individualmente quanto dos subgrupos e do conjunto total de atores que compõem um determinado sistema. Em nível micro, as redes sociais nas quais os atores estão imersos podem tanto constrangê-los quanto Ihes oferecer grandes vantagens. Em nível macro, tais redes podem dificultar ou facilitar determinados processos (comunicação, difusão, inovação etc.) dentro de um sistema. Em nível meso, subgrupos de atores, por sua vez, podem desencadear processos de especialização dentro das redes.

Fica claro que as técnicas da ARS permitem analisar as cinco patologias identificadas pelos teóricos dos sistemas deliberativos. Especificamente, situações de tight-coupling podem ser verificadas por meio de análises do grau de coesão da rede, por meio da análise de densidade, proximidade e distância entre os atores. Decoupling é facilmente verificado por meio de análises de subgrupos, entre elas: análises de ilhas (island), de blocos (blockmodeling), de cliques, k-núcleos ( $k$-core). A situação de dominação institucional, destacada na literatura, pode ser verificada por meio de análises de centralidade e poder. As outras duas patologias, dominação social e clivagens, podem

Controle Social do Bolsa Família, de Saneamento e do Idoso; (4) Conselho Municipal da Juventude, que tinha na sua composição representante do Conselho Municipal de Política sobre Drogas.

É de se esperar, por outro lado, que a conectividade do subsistema seja afetada, também, quando, na definição da composição dos conselhos, houver garantia de representação para instituições que são convidadas a enviar representantes para conselhos diferentes. Por exemplo, parece razoável que a Secretaria Municipal de Assistência Social seja indicada para ocupar uma cadeira em conselhos ligados às políticas sociais, tais como: Conselhos de Direitos da Criança e do Adolescente, do Idoso etc. Entretanto, se analisarmos a atuação dos conselheiros com conectores do subsistema no lugar das instituições, como fazemos neste artigo, perceberemos que o impacto do arranjo institucional sobre a conectividade do subsistema depende mais de processos internos nas instituições, ao se decidir quem enviar aos conselhos, do que de normas das arenas deliberativas. No subsistema dos conselhos de políticas públicas em Belo Horizonte, observamos que a maioria das organizações envia representantes diferentes para conselhos diferentes e os conselheiros que atuam em mais de duas arenas, em geral, representam mais de um órgão do poder público, ainda que haja sobreposição. Destacamos que esse é um ponto de nossa agenda de pesquisa a ser aprofundado como desdobramento de nossa pesquisa inicial.

5 É necessário fazer uma ressalva nesse ponto, na medida em que os nossos dados dizem respeito aos conselheiros que representam o poder público nos conselhos, isto é, o termo burocracia compreende um conjunto de atores mais amplo. Nesse sentido, embora parte dos conselheiros governamentais possa ser oriunda da burocracia, eles podem ser também: 1) políticos eleitos ou não que estejam desempenhando a função de secretário de Estado; 2) funcionários nomeados para os cargos de confiança de livre designação pelos políticos eleitos; 3) até mesmo um consultor indicado pelo governo. 
ser estudadas com apoio da ARS combinando dados sobre as relações entre as partes (variáveis estruturais) com características das partes componentes dos sistemas deliberativos associadas às dimensões econômicas, de consumo, ideológica, étnica, religiosa etc. (variáveis de composição).

A ARS ajuda a produzir uma interpretação realista da política, que busca compreender conjuntamente a dinâmica deliberativa, desde os corpos legislativos até as microiniciativas deliberativas. É realista porque pode incorporar no modelo variáveis características da luta cotidiana pelo poder; seja pela abordagem dos efeitos do jogo de interesses dos grupos, tal como compreendida pela competição pluralista; seja pela reprodução das desigualdades derivada do acesso diferenciado dos indivíduos aos recursos de poder, principalmente, o dinheiro e a capacidade de pressão; e, por fim, pela constatação de que o poder decisório dos formuladores de políticas e das elites (políticos e gestores) pode prevalecer sobre as deliberações oriundas das microarenas deliberativas.

Assim, podemos vencer o desafio metodológico de construir técnicas de pesquisa capazes de produzir achados empíricos que mostrem, ao mesmo tempo, a dinâmica de funcionamento das partes e seus impactos sobre o sistema deliberativo como um todo. Neste estudo, mobilizamos uma técnica específica da ARS, qual seja: análise de redes de afiliação (affiliation network analysis), conhecida também como análise de redes de dois modos (two-mode network analysis). Essa é uma ferramenta que permite estudar a relação entre dois grupos de dados de naturezas diferentes, chamados eventos e atores (Borgatti e Halgin, 2011; Nooy, Batagelj e Mrvar, 2011; Ribeiro e Andrade, 2013).

Esse tipo de abordagem permite identificar o modo como os elementos de um grupo conectam-se com os de outro grupo. Seu pressuposto fundamenta-se na ideia de que, por um lado, atores que frequentam os mesmos espaços são similares em seus gostos e atitudes. Por outro lado, os espaços que compartilham participantes tendem a ser iguais em estrutura e nas decisões que produzem, pois os atores transportam ideias, inovações e normas de uma instituição a outra. Aqui assumimos estes pressupostos e destacamos que os conselheiros, ao participar de mais de um conselho, facilitam a difusão de razões, ideias e interesses no subsistema e, assim, contribuem para o aumento da legitimidade das decisões ali produzidas.

Os dados foram coletados no dia 7 de outubro de 2014 diretamente do portal da Prefeitura de Belo Horizonte ${ }^{6}$. Levantamos o nome dos conselheiros titulares e suplentes em 22 dentre os 23 conselhos relacionados pela prefeitura. Apenas para o Conselho Municipal de Proteção e Defesa do Consumidor não encontramos informação disponível nem no portal da prefeitura de Belo Horizonte, nem através de ferramenta de busca na internet. Os dados de dois conselhos (Educação e Saúde) foram encontrados através do Google, uma vez que não havia informação sobre a composição destes no portal da

\footnotetext{
${ }^{6}$ Ver: <http://colegiados.pbh.gov.br/sgc/iFramePortalPbh.php?int_codigoColegiado=5\&tc=>.
} 
Prefeitura. Os dados foram tratados dando origem a uma matriz de incidência que apontou os conselhos de que cada conselheiro participava. Esses dados foram inseridos no software Pajek 4.01 for social network analysis e Ucinet 6.461 for social network analysis. Após esses procedimentos chegamos a uma rede de dois modos com 870 vértices, sendo 22 conselhos de política e 848 conselheiros.

\section{Resultados}

Com o objetivo de fornecer nossa contribuição ao debate, analisamos o conjunto de conselhos de políticas públicas da cidade de Belo Horizonte (MG-Brasil). Nossa abordagem é exploratória e o argumento central destaca que os conselhos formam um subsistema deliberativo, parte do sistema deliberativo mais amplo que envolve movimentos sociais, ONGs, secretarias e ministérios, Câmaras Legislativas, Executivos etc. Os conselhos de políticas são, reconhecidamente, inovações que ampliaram a democracia ao criar espaços de participação na política formal para atores tradicionalmente excluídos, nos quais o diálogo entre poder público e organizações civis pudessem ocorrer de forma mais regular. Nossa análise destaca o papel desses atores (conselheiros) como conectores das partes (os conselhos) do subsistema deliberativo de conselhos. Enquanto os conselheiros se distinguem por serem originários da sociedade civil, do poder público ou do mercado, os conselhos se diferenciam pela natureza das políticas públicas às quais estão associados. Assim, temos as seguintes categorias de conselhos: 1) políticas sociais (educação, saúde, assistência social, segurança alimentar, alimentação escolar, auxílio do transporte escolar, cultura, drogas etc.); 2) políticas urbanas (mobilidade, habitação, saneamento, turismo, desenvolvimento econômico, patrimônio histórico, meio ambiente); e 3) conselhos de direitos (juventude, mulher, idoso, criança e adolescente, igualdade racial, deficiência, consumidor).

A primeira aproximação dos dados mostra que, tal como argumentado pela teoria, os espaços deliberativos nas democracias modernas encontram-se conectados. Ao observar apenas um aspecto da conexão entre esses espaços deliberativos (a coparticipação de alguns membros), verificamos, conforme mostra a Figura 2, que o subsistema de conselhos na cidade de Belo Horizonte encontra-se completamente conectado. Alguns conselheiros, ao participarem de mais de um conselho, constituem uma classe especial de atores por meio dos quais ideias, razões e informações podem fluir de um conselho a outro. Nesse sentido, o subsistema dos conselhos de políticas em Belo Horizonte tende a produzir um maior grau de legitimidade de suas decisões, ao mesmo tempo que permite maior influência mútua entre os atores que ali atuam. 


\section{Figura 2 \\ Subsistema deliberativo dos conselhos de políticas de Belo Horizonte - Minas Gerais, Brasil - conectividade e centralidade}

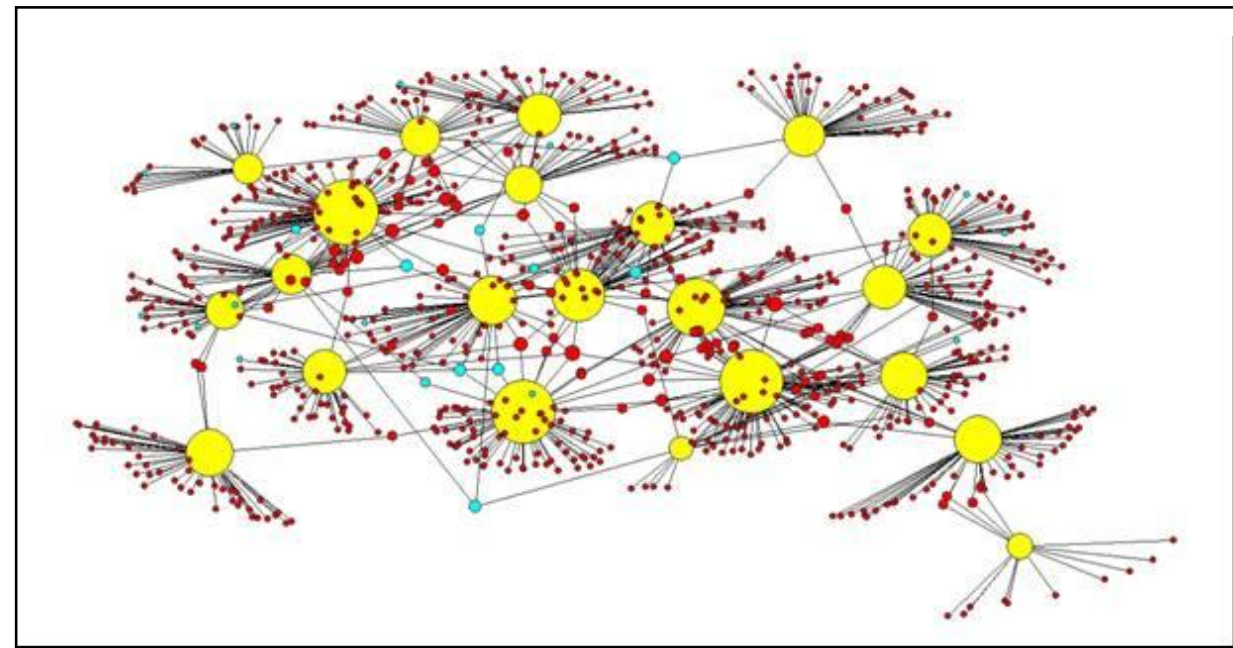

Fonte: Elaboração própria com base em dados da prefeitura de Belo Horizonte.

Legenda: Amarelo = Conselhos; Azul = Conselheiros Representantes do Poder legislativo; Vermelho $=$ Demais conselheiros.

O subsistema dos conselhos de políticas é formado por 22 conselhos e 848 conselheiros. Embora apresente uma densidade baixa $(0,05 \%)$, o subsistema possui uma alta taxa de transitividade $(0,769)^{7}$. Enquanto a primeira característica pode apontar 0 afastamento da patologia do tight-coupling e suas consequências sejam elas positivas (possibilidade de disparar mecanismos de correção) ou negativas (dificuldade de difusão de razões e informações), a segunda característica mostra que os conselhos que coafiliam conselheiros tendem a aumentar a sobreposição, enquanto conselheiros que coparticipam em um conselho apresentam uma tendência de expandir a relação de coparticipação que os associam. O fenômeno da transitividade observado pode resultar na formação de subgrupos que, por sua vez, criam um ambiente propício para a segunda patologia destacada pela literatura: decoupling. Consequentemente, para esse subsistema, reforçase a hipótese da dificuldade de se desencadear um processo de difusão de razões e opiniões.

Além da conectividade e da transitividade do subsistema, a Figura 2 mostra que alguns conselheiros são mais ativos que outros (círculos azuis e vermelhos maiores). Estes são os atores que conectam os conselhos ao participar de várias arenas do

\footnotetext{
${ }^{7}$ A densidade indica o grau de conexões estabelecidas entre as partes da rede. A transitividade diz respeito à tendência de dois conselhos, que compartilham um conselheiro, compartilharem outros conselheiros ou, por outro lado, de dois conselheiros que são coparticipantes em um conselho se tornarem coparticipantes em outros conselhos.
} 
subsistema deliberativo. Nesse caso, os mais ativos são representantes do poder público que participam, em geral, de três, quatro ou cinco conselhos ${ }^{8}$. Por outro lado, os conselhos que se destacam como aqueles que mais compartilham membros com outros conselhos são: Conselho Municipal da Assistência Social (21 conselheiros), Conselho Municipal do Idoso (19), Conselho Municipal de Política Urbana (16), Conselho Municipal de Mobilidade Urbana (16), Conselho Municipal da Promoção da Igualdade Racial (14).

A Figura 3 mostra o subsistema dos conselhos de política de Belo Horizonte, excluídos os conselheiros que participam apenas de um conselho. Nessa figura, fica mais claro que a relação entre os conselhos acontece, principalmente, em função da participação de conselheiros representantes do poder público (círculos azuis e vermelhos ${ }^{9}$ ). Entretanto, foram identificados alguns representantes da sociedade civil conectando dois conselhos (círculos verdes). Esses atores da sociedade civil desempenham uma função especial no sistema ao conectar, por exemplo, o Conselho Municipal de Saúde ( $n^{\circ} 15$ no canto esquerdo da figura) ao restante do sistema. Também se destacam ao estabelecer uma relação direta entre o Conselho Municipal de Educação ( $n^{\circ} 8$ ), o Conselho Municipal dos Direitos da Criança e do Adolescente ( $\left.n^{\circ} 19\right)$, bem como o Conselho Municipal da Cultura $\left(n^{\circ} 6\right)$ e o Conselho Municipal do Auxílio ao Transporte Escolar ( $n^{\circ} 21$ ) e os Conselhos Municipais de Assistência Social ( $n^{\circ} 5$ ) e de Pessoas Portadoras de Deficiência Física (n 10).

\footnotetext{
${ }^{8}$ Somando titulares e suplentes, identificamos 1.756 vagas ocupadas pelos conselheiros nos conselhos de Belo Horizonte. Como um mesmo ator pode estar em mais de um conselho, chegamos ao número de 848 pessoas.

${ }^{9}$ Os círculos azuis mostram a inserção dos vereadores designados para os conselhos, os vermelhos, as demais representações do poder público.
} 
Figura 3

Subsistema deliberativo dos conselhos de políticas de Belo Horizonte - Minas
Gerais, Brasil - Conectores do subsistema, receptividade e atividade

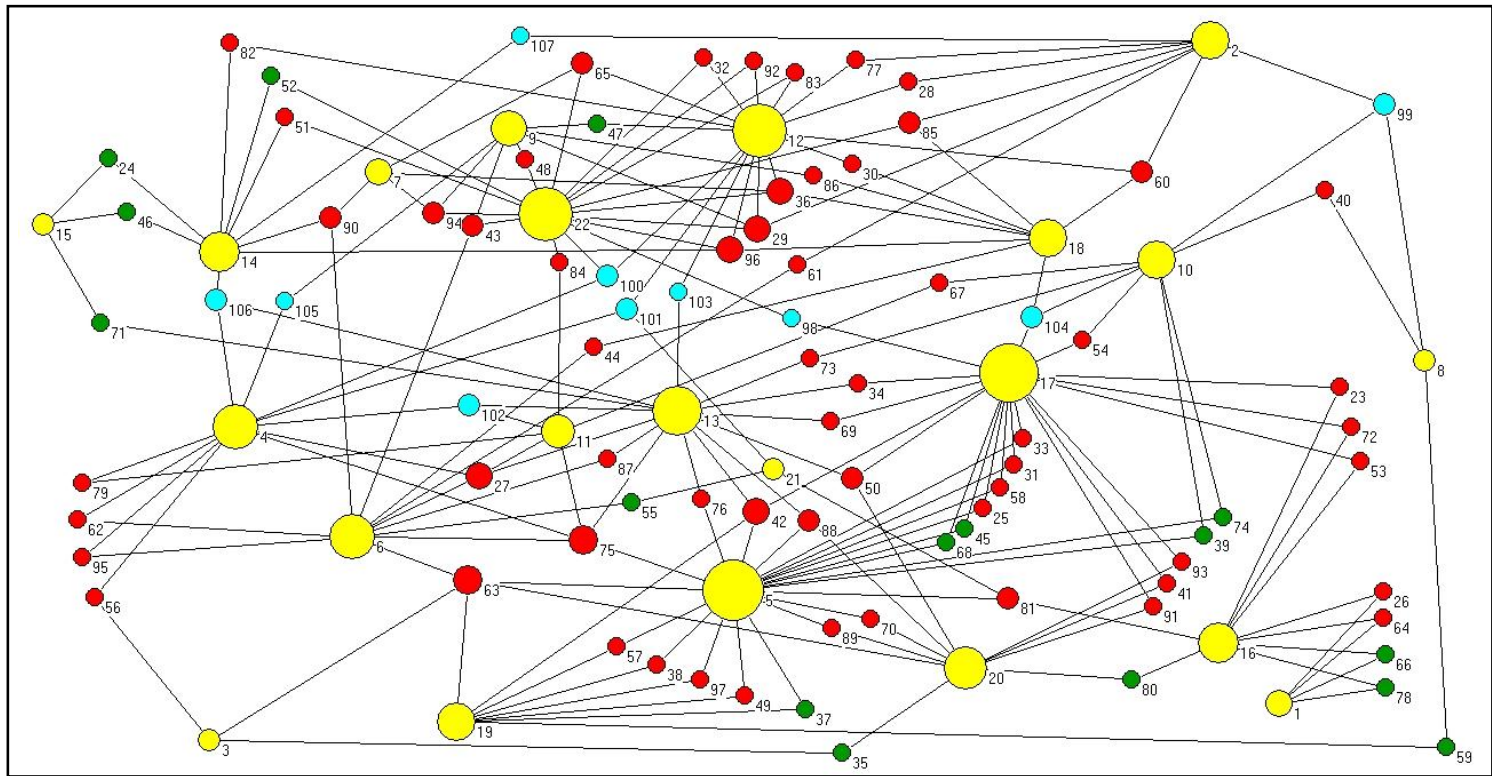

Fonte: Elaboração própria com base em dados da prefeitura de Belo Horizonte.

Legenda: Amarelo = Conselhos; Azul = Conselheiros representantes do Legislativo; Vermelho = Conselheiros representantes do Poder público; Verde $=$ Conselheiros representantes da sociedade civil.

Entretanto, a atuação dos atores da sociedade civil como conectores do subsistema dos conselhos em Belo Horizonte é tímida. Eles representam apenas 14,95\% do grupo de atores (conselheiros e conselhos) que conectam o subsistema. Além disso, os representantes da sociedade civil atuam no máximo em dois conselhos. Uma possível explicação seria a pluralidade de organizações da sociedade civil, as quais direcionam sua atuação para áreas de políticas públicas. Por exemplo, os membros de uma ONG da saúde tendem a se interessar, prioritariamente, por outras partes do sistema deliberativo ligadas à saúde: o conselho de saúde, a conferência de saúde, o movimento de saúde, as audiências públicas relacionadas à questão da saúde etc. Isso indica que esses atores encontram-se conectados em outros subsistemas e seu papel de conectores pode ser mais bem analisado em um subsistema delimitado pela temática que guia a ação política. Desse modo, não haveria razões para atuarem em conselhos de políticas que não possuíssem afinidades com as ações que desenvolvem. Sabe-se, ainda, que os custos da participação podem incidir de forma mais expressiva sobre os atores da sociedade civil, que podem não contar com o apoio financeiro de suas organizações, o que os colocaria em situação de desigualdade em relação aos atores do Estado ${ }^{10}$.

${ }^{10}$ Seria interessante analisar o perfil dos conselheiros da sociedade civil, entretanto os dados coletados no site da prefeitura não registram esse tipo de informação. Para alguns conselhos foi possível verificar que a 
Por sua vez, os representantes do poder público representam 64,49\% dos conectores do subsistema. A participação maior desse tipo de ator na função de conector do subsistema de conselhos pode ser explicada pela natureza diferente da relação entre esses atores e os conselhos. Os atores estatais podem ser nomeados à revelia da sua vontade, dependendo da pasta na qual trabalham (Secretaria da Fazenda, Secretaria do Planejamento). Diferente dos atores da sociedade civil, sua relação com o subsistema não responde exclusivamente à afinidade temática. Representantes do poder público podem ser indicados para vários conselhos, pois suas áreas de origem podem ser muito generalistas ${ }^{11}$.

Os achados apontam que a exclusão dos conselheiros da sociedade civil do subsistema de conselhos causaria poucos prejuízos para sua integração. Os representantes do poder público são os principais conectores desse subsistema, sob o ponto de vista da coafiliação. Todavia, esse achado não significa que a sociedade civil possua um papel pouco relevante para o sistema deliberativo mais amplo ou mesmo para a legitimidade das decisões produzidas no subsistema dos conselhos. Ao contrário, sua função pode estar associada à sua capacidade de conectar subsistemas formais aos subsistemas informais. Logo, considerando o sistema deliberativo em nível agregado, esses atores podem ser considerados importantes conectores de subsistemas. Eles se destacam por circular nos diferentes espaços de deliberação, conselhos de políticas, fóruns, movimentos, audiências públicas, casas legislativas etc. Em função dos diversos acoplamentos e desacoplamentos em diferentes subsistemas, representam os laços verticais da Figura 1 e, por isso, se tornam atores portadores de informações valiosas, importantes para o funcionamento adequado do sistema deliberativo. Essa é uma hipótese que deve ser trabalhada em outro momento, a análise apresentada aqui não é suficiente para testá-la, mas aponta a marginalidade desses atores enquanto conectores dos subsistemas dos conselhos de políticas públicas em Belo Horizonte, sem questionar sua importância para o sistema deliberativo.

A análise dos conectores nesse subsistema sugere, ainda, que no caso analisado houve uma especialização dos representantes do poder público na função de conselheiro, haja vista o número considerável de atores que se repetem atuando em diferentes conselhos. Alguns autores (Tatagiba, 2002; Silva, 2013; Cunha, 2013) chamam a atenção para esse fenômeno, destacando que ele é próprio de municípios de pequeno porte. O caso analisado mostra, também, o fenômeno da especialização dos

representação dos conselheiros da sociedade civil está vinculada às entidades de natureza sindical, empresarial, profissional, estudantil, cultural, religiosa e de pesquisa. São representados nos conselhos de Belo Horizonte: movimentos sociais (negro, por moradia, luta pró-creche, de mulheres, de pessoas com deficiência etc.), universidades, associações ligadas às artes, ao meio ambiente, ao esporte, fundações, hospitais, federação da indústria, federação da agricultura, entre outras.

11 Os conselhos correspondem aos $20,56 \%$ dos conectores restantes. Neste artigo não analisamos as relações entre os conselheiros a partir da coparticipação nos conselhos. Tecnicamente, isso significa que, no limite deste artigo, não analisamos a rede de um modo dos conselheiros. O tema, por si só, é discutido em outra fase da pesquisa, em análise dos possíveis problemas e perigos da participação concomitante em várias arenas deliberativas. 
representantes do Estado em uma metrópole. Esse achado leva-nos a indagar se o processo de amadurecimento das instituições participativas do tipo conselhos de políticas tornou o fenômeno da especialização dos representantes do poder público um fenômeno generalizado para esse tipo de subsistema. Por um lado, tal especialização pode ter o efeito positivo de tornar mais qualificada a atuação desses conselheiros, pelo saber acumulado no exercício da função. Por outro lado, restringe a pluralidade e a representatividade dos conselheiros governamentais.

Os dados analisados revelam, todavia, que a especialização desses conselheiros encontra-se submetida à natureza das políticas públicas às quais os conselhos estão vinculados. A coparticipação dos conselheiros vinculados ao poder público coloca em relação conselhos que trabalham com políticas da mesma natureza. A Figura 4 mostra que os conselhos compartilham mais conselheiros quando os tipos de política aos quais estão vinculados encontram-se na mesma categoria. Tal situação ocorre naquelas políticas cujas decisões originárias dos conselhos inclinam-se a se afetar mutuamente, característica que tende a reforçar a legitimidade das decisões tomadas naquela arena.

Porém, essa dinâmica presente no subsistema pode contribuir para a emergência da patologia de decoupling, haja vista que a formação de subgrupos dentro dos subsistemas pode dificultar a difusão de razões, ideias e informações, limitando, assim, o debate entre as partes do subsistema. 


\section{Figura 4 \\ Ilhas no subsistema deliberativo dos conselhos de políticas de Belo Horizonte - Minas Gerais, Brasil - Centralidade total}

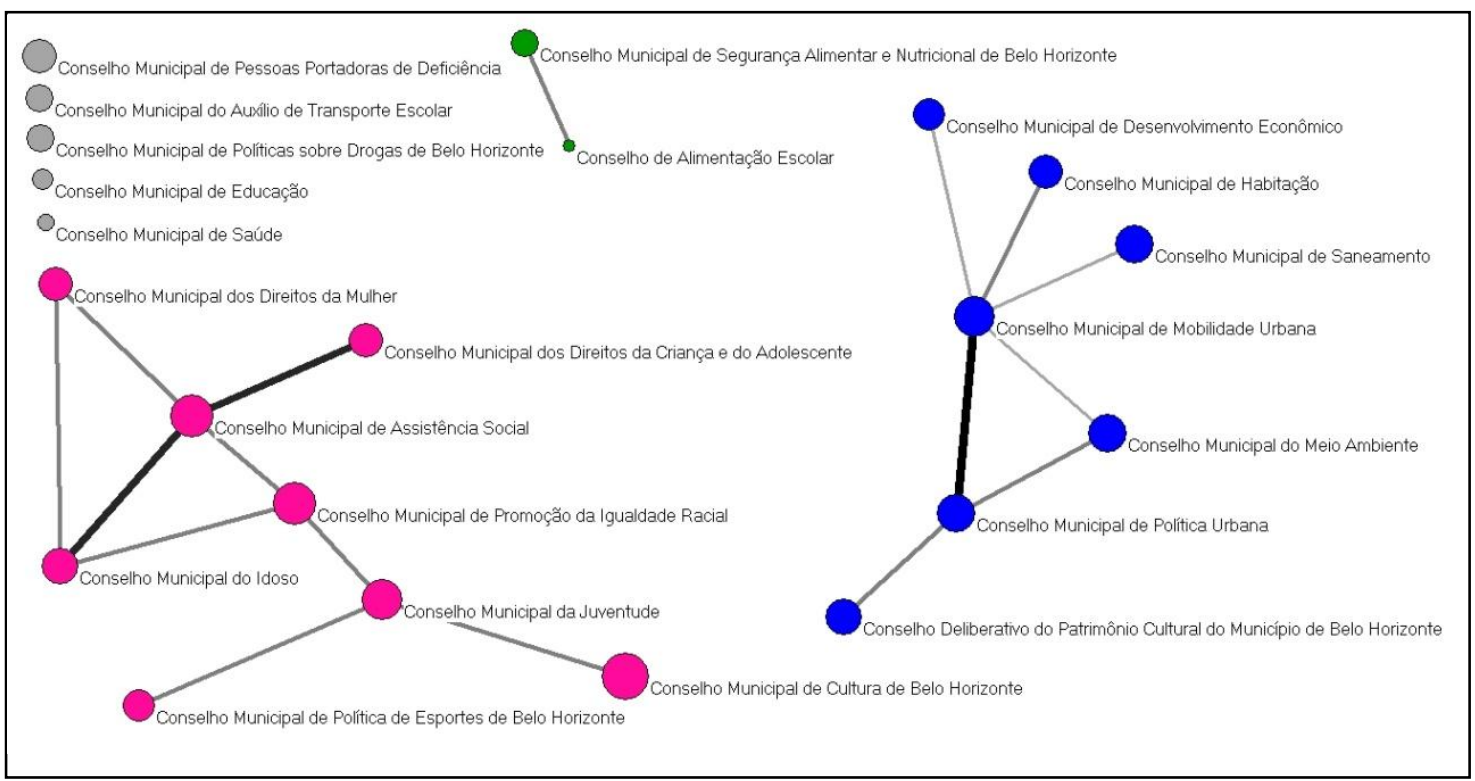

Fonte: Elaboração própria com base em dados da prefeitura de Belo Horizonte.

Legenda: Cinza = Conselhos desconectados; Verde = Ilha de conselhos ligados ao tema da alimentação; Azul = Ilha de políticas urbanas; Rosa = Ilha políticas de direitos e políticas sociais.

Para ilustrar e explorar esse achado, separamos a rede de um modo (one-mode network) de conselhos da rede de dois modos e realizamos uma análise de ilhas (island analysis). Isto é, isolamos o grupo de conselho da rede original e analisamos a forma como os conselheiros conectores estabelecem a relação entre os conselhos a partir do número de coafiliação entre eles. Essa abordagem identificou subgrupos de conselhos mais fortemente conectados entre si por compartilhar um número maior de conselheiros $^{12}$. Os subgrupos identificados (chamados ilhas) mostram os conselhos que são, provavelmente, mais similares em seus procedimentos por compartilhar um maior número de conselheiros. Considerando que as razões trocadas nos diferentes conselhos podem circular, especialmente via conselheiros compartilhados dentro do subsistema,

\footnotetext{
${ }^{12} \mathrm{~A}$ abordagem da análise de ilhas exige que o pesquisador defina o tamanho mínimo e máximo das ilhas. Isso significa definir quantidade de atores a serem incluídos nos subgrupos considerando a intensidade dos laços entre eles. Definimos o mínimo de 2 e o máximo de 9 . O número máximo só é completado quando todos os atores que se ligam ao grupo pelos laços de menor intensidade não ultrapassam 9 atores, caso isso ocorra o programa seleciona para o subgrupo o número mais próximo do máximo definido, mas ligados pela mesma intensidade à ilha. Metaforicamente, essa situação é similar a dizer que só podem participar de uma festa atores que são queridos na mesma intensidade pelo grupo, respeitando a capacidade máxima de lotação do espaço onde a festa ocorrerá. Caso a lotação da festa seja de 20 pessoas e os atores que ocupam a posição de 19 a 25 na lista que classifica a intensidade de amizade entre os possíveis convidados para a festa sejam ligados ao grupo dos 18 convidados que são mais amigos entre si, todos os 7 atores ficarão de fora da festa e os 2 convites restantes não serão distribuídos.
} 
isso seria mais provável de ocorrer entre as ilhas de conselhos encontradas. Nosso argumento destaca que a legitimidade das decisões ali produzida tende a ser reforçada.

Há, no subsistema de conselhos, três ilhas definidas: uma pequena ilha com dois conselhos (cor verde), composta pelos Conselhos Municipais de Segurança Alimentar e Nutricional e os Conselhos de Alimentação Escolar, sendo clara a relação entre as duas políticas. Esses conselhos compartilham quatro conselheiros (dois do poder público e dois da sociedade civil). Nesse subgrupo, o grau de conexão ${ }^{13}$ dos conselhos dentro do subsistema analisado mostra que o primeiro conselho encontra-se mais conectado ao subsistema, embora fracamente, pois o Conselho de Alimentação Escolar compartilha poucos membros com outras arenas do subsistema.

Uma segunda ilha chama atenção e encontra-se à direita na Figura 4 na cor azul. Essa é composta por conselhos associados, de um modo geral, às políticas urbanas. Ela reúne os Conselhos Municipais de Desenvolvimento Econômico, Habitação, Saneamento, Mobilidade Urbana, Meio Ambiente, Política Urbana e Patrimônio Cultural. Uma característica marcante dessa ilha é a posição central ocupada pelo Conselho Municipal de Mobilidade Urbana, o que mais compartilha membros dentro desse subgrupo. Em função dessa posição, esse conselho é o que oferece as melhores condições para acessar informações sobre os debates em relação à questão de desenvolvimento e planejamento da cidade. Tal característica poderia revelar a possibilidade de ocorrência da patologia de dominação institucional dentro do subgrupo. Do ponto de vista dos conselheiros, tornarse conselheiro nessa instituição pode trazer grandes vantagens ao indivíduo. Destaca-se, ainda, sua forte relação com o conselho municipal de política urbana. Entretanto, dada a configuração geral do subsistema analisado, nenhum conselho apresentou condições de dominar todo o subsistema deliberativo dos conselhos da cidade de Belo Horizonte.

A terceira ilha do subsistema é formada por um conjunto de conselhos ligados às políticas de direitos e às políticas sociais (cor rosa). Constatamos que essa parte do subsistema encontra-se fracamente dividida. Há, no subsistema deliberativo dos conselhos, a presença de um setor organizado em torno do Conselho de Juventude. Em parte, isso pode ser reflexo de uma concepção de política de juventude que envolve diretamente as políticas de esporte, cultura e promoção da igualdade racial. Por outro lado, os conselhos de políticas de direitos se organizam em torno do Conselho Municipal de Assistência social, no qual se observou uma forte relação entre esse conselho e os Conselhos Municipais de Direitos da Criança e do Adolescente e do Idoso. Essa relação com o Conselho de Assistência Social pode ser explicada, principalmente, em função das suas conexões com a área da criança e do adolescente e do idoso. Certamente, isso

\footnotetext{
13 O tamanho dos círculos mostra o grau de conexão de um conselho com todos os outros. Assim, os círculos maiores representam conselhos que mais compartilham conselheiros dentro do subsistema. Entretanto, alguns conselhos nessa situação compartilham apenas um conselheiro com outros conselhos. Isto é, eles estão fracamente conectados com outros conselhos considerando que os pares identificados nas ilhas compartilham de 3 a 8 conselheiros. A intensidade desses laços é indicada na Figura 4 pela espessura e cor das linhas. As conexões fortes estão representadas por linhas mais grossas e mais escuras.
} 
SISTEMAS DELIBERATIVOS EM PERSPECTIVA MESO

deriva das normativas das políticas e da presença dos equipamentos públicos relacionados à promoção dos serviços nessas áreas (asilos, centros de passagem, abrigos etc.).

Podemos verificar, ainda, a presença - no subsistema deliberativo analisado - de cinco conselhos municipais fracamente conectados via coafiliação dos conselheiros (cor cinza). Os conselhos municipais de pessoas portadoras de deficiência, auxílio de transporte escolar, políticas sobre drogas, educação e saúde estão menos integrados ao subsistema. Embora alguns compartilhem poucos conselheiros com muitos conselhos do subsistema, nenhum dos cinco conselhos se conectou aos subgrupos que existem no subsistema. Consequentemente, esses são os espaços deliberativos nos quais as decisões são construídas com menos probabilidade de se tomar em conta as razões presentes em outros conselhos. Assim, são conselhos que precisam encontrar outros mecanismos para reforçar a legitimidade de suas decisões.

\section{Considerações finais}

Propusemos no artigo uma proposta metodológica para captar os avanços teóricos sugeridos pela literatura sobre os sistemas deliberativos, que tem sido utilizada, no Brasil, para o estudo das instituições participativas. Para tanto, criou-se uma estratégia analítica de identificar subsistemas deliberativos no interior do sistema político brasileiro. Três critérios orientaram a identificação e a caracterização do subsistema: 1) natureza da instituição; 2) territorialidade; 3) área temática de política pública. Com o propósito de verificar as condições para a deliberação em larga escala, considerando-se tanto a pluralidade de atores quanto a vasta extensão territorial dos regimes democráticos contemporâneos, buscou-se se analisar o subsistema deliberativo dos conselhos da cidade de Belo Horizonte.

Apresentou-se uma caracterização do modelo sistêmico proposto por Mansbridge et al. (2012), com o intuito de analisar suas particularidades e potencialidades. Em seguida, procurou-se explicitar as dificuldades derivadas da aplicação do modelo para a realização de pesquisas empíricas. Realizou-se uma revisão da literatura nacional que tem partido do modelo sistêmico para produzir estudos sobre as instituições participativas. Foi possível observar avanços na proposição de modelos mais amplos de análise, capazes de incorporar diversas dimensões do funcionamento das instituições participativas analisadas. No entanto, os estudos ainda estão muito concentrados na análise de instituições de uma mesma área temática de política pública. Mesmo os estudos que introduziram mais de uma área temática na pesquisa, ainda não conseguiram mostrar as conexões existentes entre as diferentes áreas de políticas públicas. Também é preciso avançar para a construção de estudos capazes de captar as conexões entre as diferentes partes do sistema.

Diante desses desafios, procurou-se construir um modelo de análise exploratório capaz de incluir 22 áreas temáticas de políticas públicas, que contam com a participação 
de mais de 800 conselheiros. Com base nessas informações, procurou-se verificar quais seriam os conselhos que compartilham a participação dos mesmos atores com outros conselhos. Por outro lado, procurou-se também investigar os atores com participação em vários conselhos, que pudessem, assim, fazer alguma conexão entre essas diferentes instituições. Em outras palavras, diante da dificuldade de realizar estudos empíricos capazes de indicar os conectores dos sistemas deliberativos, empreendeu-se uma investigação que pudesse identificar as possíveis conexões estabelecidas entre os 22 conselhos de políticas públicas de Belo Horizonte.

Os resultados encontrados permitem afirmar a existência de conselheiros que participam de vários conselhos. Nesse sentido, podem ser considerados elos de conexão entre as instituições, uma vez que as experiências vivenciadas em cada instituição podem ser compartilhadas com as demais nas quais esse ator se faz presente. Principalmente, quando as áreas temáticas são afins, é possível que a experiência vivenciada em um conselho possa ser compartilhada com os conselheiros de outras áreas, favorecendo o intercâmbio de informações e a comunicação entre as áreas. A especialização na função de conselheiro pode ser benéfica para os conselhos, que terão um conselheiro experiente atuando. No entanto, pode expressar também a limitação da expressão da pluralidade e da representatividade do próprio Estado nos conselhos, uma vez que um único representante exerce a função em vários espaços.

A análise de ilhas revelou a existência de subgrupos dentro do subsistema de conselhos de Belo Horizonte, fortemente conectados, e a presença de um conjunto de conselhos menos conectado ao sistema. Entretanto, resta investigar a conexão dos conselhos da cidade com outros espaços deliberativos. Ou seja, é preciso investigar como esse subsistema deliberativo se integra ao restante do sistema deliberativo da cidade. A análise apresentada aqui mostra que os representantes do poder público em Belo Horizonte são importantes conectores do subsistema de conselhos, o que não acontece com os atores da sociedade civil. Sobre estes coube levantar a hipótese de que eles podem ser os principais elos entre o subsistema de conselhos com outros subsistemas do sistema deliberativo geral.

Eduardo Moreira da Silva - Departamento de Ciência Política. Faculdade de Filosofia e Ciências Humanas. Universidade Federal de Minas Gerais. Residente pós-doutoral. E-mail: <eduardovirtual2014@gmail.com>.

Antonio Carlos Andrade Ribeiro - Professor do Departamento de Ciências Humanas. Universidade Federal de Alfenas. Doutorando em Sociologia. Departamento de Sociologia. Faculdade de Filosofia e Ciências Humanas. Universidade Federal de Minas Gerais. E-mail:<antonilos@gmail.com>. 


\section{Referências bibliográficas}

AlmeidA, D. C. R. "Resenha do livro Deliberative systems: deliberative democracy at the large scale". Revista Brasileira de Ciência Política, Brasília, vol. 11, p. 243-255, 2013.

AVRITZER, L. Participatory institutions in democratic Brazil. Baltimore: Johns Hopkins University Press, 2009.

Avritzer, L. (org.). A dinâmica da participação local no Brasil. São Paulo: Cortez Editora, 2010.

Bohman, J. Public deliberation: pluralism, complexity and democracy. New Basrkerville: MIT, 1996.

. Representation in the deliberative system. In: PARKInSON, J.; MANSBRIDGe, J. (orgs.).

Deliberative systems. New York: Cambridge University Press, p. 72-94, 2012.

Borgatti, S.; Halgin, D. Analyzing affiliation networks. In: CARrington, P. J.; ScotT, J. (eds.). The Sage Handbook of Social Network Analysis. Sage Publications, cap. 28, 2011.

Chambers, S. Deliberation and mass democracy. In: PARKinson, J.; MANSBRidge, J. (orgs.). Deliberative systems. New York: Cambridge University Press, p. 52-71, 2012.

Christiano, T. Deliberation among experts and citizens. In: PARKInson, J.; MANSBRidge, J. (orgs.). Deliberative systems. New York: Cambridge University Press, p. 72-92, 2012.

CunHA, E. S. "Análise da deliberação em conselhos de Minas Gerais". In: III Workshop Internacional Pronex/Fapemig, Lisboa, 6 e 7 de julho de 2013.

CUNHA, E. S.; ALmEIDA, D. R. "Sociedade civil e representação nas arenas deliberativas da assistência social no Brasil". In: LASA'S XXXI International Congress, Washington-DC, 29 May - $1^{\text {st }}$ June of 2013.

DRYZEK, J. S. Deliberative turns. In: DRYZEK, J. S. Foundations and frontiers of deliberative governance. New York: Oxford University Press, cap. 1, p. 3-17, 2010.

FARIA, C. F.; LINS, I. L. Participação e deliberação nas conferências de saúde: do local ao nacional. In: Avritzer, L.; SouzA, C. H. L. (orgs.). Conferências Nacionais: atores, dinâmicas participativas e efetividades. Brasília: Ipea, p. 73-94, 2013.

FARIA, C. F.; SilVA, V. P.; LINS, I. L. "Conferências de políticas públicas: um sistema integrado de participação e deliberação?". Revista Brasileira de Ciência Política [online], Brasília, n 7, p. 249-284, 2012.

FUnG, A. Receitas para esferas públicas: oito desenhos institucionais e suas consequências. In: SChatTAN, V.; NoBre, M. (orgs.). Participação e deliberação. São Paulo: 34 Letras, 2004.

Habermas, J. "Três modelos normativos de democracia". Lua Nova, São Paulo, n 36, p. 39-53, 1995. Direito e democracia: entre facticidade e validade. Vol. II. Rio de Janeiro: Tempo Brasileiro, cap. VII e VIII, 2003.

MACKENZIE, M. K.; WARREN, M. E. Two trust-based uses of minipublics in democratic systems. In: PARKInSON, J.; MANSBRIDGE, J. (orgs.). Deliberative systems. New York: Cambridge University Press, p. 95-124, 2012.

MACPherson, C. B. A democracia liberal: origens e evolução. Rio de Janeiro: Zahar, p. 97-116, 1978. 
MANSBRidge, J. A conversação cotidiana no sistema deliberativo. In: MARQUES, Â. C. S. (org. e trad.). A deliberação pública e suas dimensões sociais, políticas e comunicativas [textos fundamentais]. Belo Horizonte: Autêntica, 2009.

MANSBRIDGE, J., et al. A systemic approach to deliberative democracy. In: PARKINSON, J.; MANSBRIDGE, J. (orgs.). Deliberative systems. New York: Cambridge University Press, p. 1-26, 2012.

MendonçA, R. "The conditions and dilemmas of deliberative systems". In: APSA 2013 Annual Meeting Paper. 2013. Disponível em SSRN: <http://ssrn.com/abstract=2303025>. Acesso em: 19 out. 2013.

Nooy, W.; BATAgeL, V.; MRVAR, A. Exploratory social network analysis with pajek. New York: Cambridge University Press, cap. 5, 2011.

PAPADOPOULOS, Y. On the embeddedness of deliberative systems: why elitist innovations matter more. In: PARkinson, J.; MANSBRIDGE, J. (orgs.). Deliberative systems. New York: Cambridge University Press, 2012. p.125-150.

PARKINSON, J. Deliberating in the real world: problems of legitimacy in deliberative democracy. Oxford: Oxford University Press, 2006.

. Democratizing deliberative systems. In: PARKInSON, J.; MANSBRIDGE, J.(orgs.). Deliberative Systems. New York: Cambridge University Press, p.151-172, 2012.

PARKInSON, J. MANSBRIDGe, J. (orgs.). Deliberative systems. New York: Cambridge University Press, 2012.

Pateman, C. Participação e teoria democrática. Rio de Janeiro: Paz e Terra, p. 9-63, 1992.

Pavez, T. R.; Toledo, D. G. C.; Gonçalves, R. R. Atores e redes no debate de segurança pública. In: MARQUES, E. C. (org.). Redes sociais no Brasil: sociabilidade, organizações civis e políticas públicas. Belo Horizonte: Fino Traço, p. 305-304, 2012.

PIRES, R. R. C. (org.). Efetividade das instituições participativa no Brasil: estratégias de avaliação. Brasília: Ipea, 2011.

Ribeiro, A. C.; ANDRADE, M. T. S. "A rede Mercocidades: a participação dos atores locais na integração regional sul-americana". In: XXIX Congreso Latinoamericano de Sociologia, Santiago, Chile, 2013.

SiLVA, E. M. "As ressignificações da representação e da legitimidade política: um estudo sobre representantes no CEDCA-MG". Tese de Doutorado em Ciência Política. Universidade Federal de Minas Gerais, Belo Horizonte, 2013.

. "O desenho institucional dos conselhos municipais dos direitos das crianças e dos adolescentes em municípios de pequeno e médio porte de Minas Gerais". In: III Workshop Internacional Pronex/Fapemig, Lisboa, 6-7 jul. 2013.

. "Sistemas deliberativos e análise de redes: similitudes e diferenças nas pesquisas sobre instituições participativas". In: Anais do IX Encontro da Associação Brasileira de Ciência Política, Brasília, 2014.

TATAGIBA, L. Os conselhos gestores e a democratização das políticas públicas no Brasil. In: DAGnino, E. (org.). Sociedade civil e espaços públicos no Brasil. São Paulo: Paz e Terra, p. 47-103, 2002.

YounG, I. M. Representation and social perspective. In: YounG, I. M. Inclusion and democracy. New York: Oxford University Press, Introdução, cap. 1-4, e-book, 2000. 


\title{
Resumo
}

Sistemas deliberativos em perspectiva meso: a abordagem dos subsistemas aplicada aos conselhos de políticas públicas em Belo Horizonte

Este artigo realiza um diálogo crítico com a literatura sobre sistemas deliberativos. Propomos uma abordagem em nível meso, nomeada aqui de "subsistema deliberativo", a fim de orientar as pesquisas empíricas nesse campo. Utilizamos técnicas de análise de redes sociais (ARS) para aplicarmos essa abordagem ao subsistema de conselhos de políticas públicas da cidade de Belo Horizonte, Minas Gerais, Brasil. Partimos da hipótese de que os principais elos de conexão entre os conselhos seriam mecanismos informais que conectam os conselhos. Os resultados indicam que os conselheiros governamentais fazem parte de vários conselhos simultaneamente, portanto, atuam como elos de conexões no subsistema analisado. Apontamos a necessidade de realizar pesquisas futuras capazes de indicar a conexão dos conselhos com outros subsistemas.

Palavras-chave: sistemas deliberativos; conselhos de políticas; democracia deliberativa; análise de redes sociais

\begin{abstract}
Deliberative systems in meso perspective: the approach of subsystems applied to public policy councils in Belo Horizonte

This article presents a critical dialogue with the literature about deliberative systems. It features an innovative proposal to investigate deliberative arenas in their connections with other parts of the political system and society. It adopts a method present in the field of Social Network Analysis (SNA) to conduct an empirical investigation of public policy councils of the city of Belo Horizonte. Our working hypothesis was that the main links among the councils would be informal mechanisms that promotes institutional interaction. The results show that government councillors are part of various councils simultaneously, so they play the role of links between the practices and institutions in which they work. It suggests the necessity to carry out future studies that would be able to show the connection of councils to the other parts of the broader deliberative system.
\end{abstract}

Keywords: deliberative systems; policy councils; deliberative democracy; social network analysis

\section{Resumen}

Sistemas de deliberación en perspectiva meso: el enfoque de los subsistemas aplicados a los consejos de políticas públicas en Belo Horizonte

En el artículo se presenta un diálogo crítico con la literatura que trata acerca de sistemas deliberativos. Se propone una aproximación al nivel meso, denominada aquí 'subsistema deliberativo', con el fin de orientar las investigaciones empíricas en este campo. Son usadas técnicas del Análisis de Redes Sociales (ARS) sobre el subsistema de consejos de políticas públicas de la ciudad de Belo Horizonte (estado de Minas Gerais, en Brasil). Se parte de la hipótesis de que los principales lazos que conectan los consejos entre sí estarían conformados por mecanismos informales. Los resultados indican que los consejeros gubernamentales forman parte da varios consejos de manera simultánea y que, por lo tanto, actúan como lazos vinculantes en el subsistema analizado. Se señala la necesidad de efectuar investigaciones futuras capaces de establecer una conexión de los consejos con otros subsistemas.

Palabras clave: sistemas deliberativos; consejos de políticas; democracia deliberativa; analisis de redes sociales 


\section{Résumé}

Systèmes délibératifs en perspective méso: l'approche des sous-systèmes appliquée aux conseils de politique publique à Belo Horizonte

Cet article propose un dialogue critique avec la littérature concernant les systèmes délibératifs. Il propose une approche au niveau méso, ici nommée "sous-système délibératif", afin de guider les recherches empiriques dans ce domaine. Cette approche est faite à partir de l'application des techniques d'analyse des réseaux sociaux (ARS) au sous-système de conseils de politiques publiques de la ville de Belo Horizonte, Minas Gerais, au Brésil. On est parti de I'hypothèse selon laquelle les principaux liens de connexions entre les conseils seraient des mécanismes informels les connectant entre eux. Les résultats obtenus indiquent que les administrateurs gouvernementaux font partie de plusieurs conseils d'administration en même temps, de sorte qu'ils agissent comme des maillons de connexions dans le sous-système analysé. Finalement, cet article souligne la nécessité de poursuivre des recherches qui pourraient établir une connexion entre les conseils et d'autres sous-systèmes.

Mots clés: systèmes délibératifs; des conseils stratégiques; la democratie deliberative; analyse des réseaux sociaux

Artigo submetido à publicação maio de 2015. Versão final aprovada janeiro de 2016. 